\title{
RainCast: A Rapid Update Rainfall Forecasting System for New Zealand
}

\section{Sijin Zhang ( $\sim$ zsjzyhzp@gmail.com )}

New Zealand Meteorological Service https://orcid.org/0000-0002-3456-8628

\section{Gerard Barrow}

New Zealand Meteorological Service

Iman Soltanzadeh

New Zealand Meteorological Service

\section{Graham Rye}

New Zealand Meteorological Service

Yizhe Zhan

New Zealand Meteorological Service

\section{Chris Webster}

New Zealand Meteorological Service

\section{Chris Noble}

New Zealand Meteorological Service

\section{Research Article}

Keywords: rainfall, nowcasting, NWP, seamless prediction

Posted Date: November 1st, 2021

DOI: https://doi.org/10.21203/rs.3.rs-1026587/v1

License: (c) (i) This work is licensed under a Creative Commons Attribution 4.0 International License.

Read Full License 


\section{RainCast: a rapid update rainfall}

\section{2 forecasting system for New Zealand}

\section{${ }^{\mathrm{a}}$ Meteorological Service of New Zealand Ltd, Wellington, New Zealand}

6 Corresponding author: Sijin Zhang (30 Salamanca Road, Kelburn, Wellington 6012,

7 sijin.zhang@metservice.com)

Abstract

RainCast is a rapid update forecasting system that has been developed to improve short-range rainfall forecasting in New Zealand. This system blends extrapolated nowcast information with multiple forecasts from numerical weather prediction (NWP) models to generate updated rain forecasts every hour. It is demonstrated that RainCast is able to outperform the rainfall forecasts produced from NWP systems out to 24 hours, with the greatest improvement in the first 3-4 hours. The limitations of RainCast are also discussed, along with recommendations on how to further improve the system.

Keywords: rainfall, nowcasting, NWP, seamless prediction

\section{Statements and Declarations}

The authors declare no conflicts of interest. 


\section{Introduction}

39 Short-range quantitative precipitation forecasting (QPF) plays an important role in both meteorological and

40 hydrological risk management. Traditionally QPF can be obtained through either a complex NWP model (e.g.,

41 Benjamin et al., 2004, 2016; Skamarock et al., 2008; Sun et al., 2012; Wilson and Roberts, 2006), or a relatively

42 straightforward statistical approach (e.g., Bowler et al., 2006; Haiden et al., 2010; Seed, 2004). In an operational

43 environment a meteorologist may take the inputs from both methods and, after considering other meteorological

44 factors, adjust them to produce finalized QPF guidance.

There have been substantial improvements in NWP forecasts since the 1990's, arising from improved data assimilation and better observations (e.g., Barker et al., 2004; Snyder and Zhang, 2003; Huang et al., 2009; Sun et al., 2010; Xiao et al., 2007; Zhang et al., 2014). For example, as one of the most used global models at the Meteorological Service of New Zealand (MetService), the Global Forecasting System (GFS) from the National Centers for Environmental Prediction (NCEP) has shown noticeable improvements, including in QPF (e.g., Wang et al., 2013), after the introduction of the hybrid ensemble variational assimilation scheme in 2012. Improvements from global NWP models can be further "localised" by running a high-resolution limited area model (LAM). For most regional forecasting centres, the focus is on significant local weather and sudden weather changes. Consequently, over the last few decades, extensive efforts have been made in the development of rapidly updating forecasting systems using as many local observations as possible, and at the same time taking the boundary conditions from the global NWP. A good example is the UK Met Office's hourly cycling convective scale UKV forecast model, which was implemented operationally in 2017 (Millan et al., 2019).

However, a state-of-the-art NWP-based rapid cycling system needs significant computational resources which most regional centres cannot afford. Additionally, the challenges of having and maintaining the expertise in observation quality control, forecast model development and data assimilation make the implementation of such a system difficult for many local weather authorities. To establish the capability of producing frequently updating QPF with lower resource requirements compared to NWP, many statistical predication systems have been developed and widely used in regional operational centres. The statistical system usually uses local observations (e.g., radar) in near real time to provide Eulerian or Lagrangian persistence-based nowcasts (e.g., Dixon and Wiener, 1993; Bowler et al., 2006; Browning, 1980). Some of them are also capable of incorporating NWP information to fill the gap between nowcast and NWP forecasts, and also extend the system's useful lead time. A good example for such a statistical system is the Short-Term Ensemble Prediction System (Bowler et al., 2006, Seed, 2003; Seed et al., 2013), also called STEPS, which is an ensemble-based probabilistic precipitation forecasting scheme that blends an extrapolation nowcast with a downscaled NWP forecast.

At MetService, STEPS has been adapted to create a rapid update rainfall forecasting system called "RainCast". Multiple NWP models are blended with an extrapolation-based nowcast from STEPS to form a "super ensemble" forecast which is updated every hour. The ensembles are then further enhanced by the neighborhood probability 

September 2020, and the findings from this project along with the details of the system are presented in this paper.

The methods used in RainCast are described in Section 2, followed by a case study of an event which occurred between 00Z and 03Z 14 June 2021 in Section 3. Section 4 provides an objective verification skill score for RainCast and compares it to the NWP models used at MetService. The limitations of RainCast are discussed in Section 5, and a short summary is provided in Section 6.

\section{2. Methodology}

RainCast is based on the STEPS algorithm described by Bowler et al. (2007). In RainCast, multiple independent STEPS tasks based on different NWP models are triggered simultaneously to create a cluster of "super ensemble" members every hour. The subjective evaluation from forecasters at MetService suggests that even with the "super ensemble", the spread of ensemble members is not sufficient to handle all rain situations accurately, particularly during severe convection events. To address this, the neighborhood probability method (e.g., Evans et al., 2018) is introduced as a post-processing step in RainCast. In this section, the adapted STEPS algorithm is briefly introduced (Section 2.1) followed by the neighborhood probability method (Section 2.2).

\subsection{Adapted STEPS}

The adapted STEPS algorithm is briefly described in this section. The algorithm takes the essential components from the native STEPS approach (e.g., Bowler et al., 2007; Seed et al., 2013) and uses a simplification scheme to run it efficiently in the operational environment.

The two main purposes of STEPS are:

(1) Combine the extrapolation-based nowcast (e.g., from radar data and usually with a forecast lead time of less than 1-2 hours), with NWP data to provide a smooth transition.

(2) Generate probability rainfall forecasts through a stochastic scheme for representing the unrecognizable features from both the extrapolation method and NWP models.

102

103

Radar data extrapolation at MetService is carried out using the Lagrangian persistence method described by Germann and Zawadzki (2002). This scheme moves radar echoes along the Optical Flow (OF) stationary motion fields:

$$
\frac{d F}{d t}=\frac{\partial F}{\partial t}+\frac{d x}{d t} \frac{\partial F}{\partial x}+\frac{d y}{d t} \frac{\partial F}{\partial y}
$$

107 where $F$ represents the radar echo to be moved, and the terms $\frac{d x}{d t}$ and $\frac{d y}{d t}$ are the OF winds which stay the same during the period of extrapolation.

110 The extrapolation-based nowcast is then blended with NWP forecasts in spectral space, and the spatial scales 111 which are not solvable by the NWP models nor extrapolation-based nowcasts are represented by a stochastic noise 112 term (e.g., Seed et al., 2013; Lovejoy and Schertzer, 2006). To achieve this, the extrapolation and NWP data are 113 first decomposed into multiple cascades using: 
115 where $R$ represents the rainfall field, and $N$ is the number of cascade levels. $X_{k}(t)$, which can be derived from the

116 Fast Fourier Transform (FFT), is the decomposed rainfall field with frequency $w_{k}$ in the range between $\frac{q^{k-1}}{L}$ and

$117 \frac{q^{k}}{L}$ at time $t$ ( $q$ is the ratio of the scales at the level $k$ and $k+1$, and $L$ represents the domain size).

119 Note that, in this study, $R$ is obtained as decibels of rain rate $(d B R)$, defined by:

$$
d B R=10 \log _{10}(R+c)
$$

121 The $d B R$ relation provides a distribution close to Gaussian, and the arbitrary small positive number $c$ simplifies

122 the treatment of dry areas. Details about the rainfall decomposition process can be found in Seed et al. (2013).

124 The ensemble members are created based on the perturbation of the NWP/nowcast cascades using a spatially correlated noise term, which is scale-dependent and temporally independent. At each cascade level, the scale information from a reference background (e.g., the NWP model) is incorporated into the noise as:

$$
\delta_{k}=G_{k, r e f} \delta^{\prime}{ }_{k}
$$

128 where $G_{k, r e f}$ is the absolute value of the reference background at the cascade level $k$, and $\delta^{\prime}{ }_{k}$ is the original noise at the same cascade level derived from the Gaussian distribution.

131 The ensemble member, $i$, can then be created by combining the scale-dependent NWP forecast $X_{k, n w p}(t)$, the extrapolation nowcast $X_{k, \text { ext }}(t)$ and the noise term $\delta_{k}$ :

$$
F(t)=\sum_{k=1}^{N} \omega_{k, n w p} X_{k, n w p}(t)+\omega_{k, e x t} X_{k, e x t}(t)+\omega_{k, n o i s e} \delta_{k}
$$

where $\omega_{k, n w p}, \omega_{k, \text { ext }}$ and $\omega_{k, \text { noise }}$ are the weights for different forecast terms, which are estimated during runtime and updated dynamically. $\omega_{k, n w p}\left(\omega_{k, \text { ext }}\right)$ is calculated from the aggregated correlation coefficient between the

136 NWP forecast (the extrapolation-based nowcast) and the corresponding radar derived quantitative precipitation estimate (QPE) over the previous 6 hours.

139 In this study $\omega_{k, n w p}$ is not lead-time dependent due to the assumption that the NWP skill does not change

140 significantly over a short period. On the other hand, $\omega_{k, \text { ext }}$ is calculated depending on the lead time from $T+1 \mathrm{~h}$

141 to $T+6 h$, and after 6 hours it is assumed that the extrapolation-based nowcast has no skill for all cascade levels 142 and therefore $\omega_{k, \text { ext }}=0$.

144 The weights for NWP, nowcast and noise terms are calculated by:

$$
\omega_{k, n w p}=\frac{\sigma_{k, n w p}}{\psi_{k}}
$$

$$
\omega_{k, e x t}=\frac{\sigma_{k, e x t}}{\psi_{k}}
$$

$$
\omega_{k, n o i s e}=1-\left(\omega_{k, n w p}+\omega_{k, \text { ext }}\right)
$$


where $\sigma_{k, n w p}$ and $\sigma_{k, \text { ext }}$ are the aggregated correlation coefficients for NWP and extrapolation-based nowcasts,

149 respectively. In this paper, the gridded New Zealand national Quantitative Precipitation Estimate (QPE) is considered as "ground truth".

$152 \psi_{k}$ is the expected forecast skill at the scale $k$. Given that the expected skill $\psi_{k}=1$ (full skill), the blended forecast can be dominated by $\delta_{k}$ if the skills for the NWP and nowcast are both low, and this would lead to an inconsistency from cycle to cycle in RainCast. Therefore, in the operational environment at MetService, $\delta_{k}$ is usually assigned a smaller value, especially at a small spatial scale, to maintain some contribution from the NWP and nowcast systems.

\subsection{Neighborhood processing method}

At MetService, NWP-based forecasts are available from several global forecasting centers such as the European Centre for Medium-Range Weather Forecasts (ECMWF), National Centers for Environmental Prediction (NCEP) and the UK Met Office (UKMO). An in-house Limited Area Model (LAM) based on the Weather Research and Forecasting (WRF) model is also run using initial conditions from the global models above. All the available

163 NWP models are used as independent candidates for triggering the adapted STEPS system described in Section

164 2.1. The outputs from the individual STEPS runs are weighted and then combined using the neighborhood process (NP) method, as described below.

NP is developed because it is unrealistic to expect high-resolution forecast models to be completely accurate at the grid scale. It is widely used in many operational forecast centers for a variety of meteorological fields including precipitation, hail, updraft helicity and lightning (e.g., Theis et al., 2005; Roberts and Lean 2008; Jirak et al., 2012; Clark et al., 2013; Schwartz and Sobash, 2017; Gagne et al. 2015; Sobash et al., 2011; Lynn et al. 2015). Several NP techniques have been developed (e.g., Schwartz and Sobash, 2017), and the one used in RainCast is briefly introduced below.

From Figure 1a, two grid points ("A" and "B") each have a $100 \%$ probability of rain for a certain threshold. Assuming that the influential grid range is 1, then after NP (Figure 1b), 16 grid points within the influential range are considered each to have a probability of rain of $11.1 \%$, while one grid will have a probability of $22.2 \%$. The NP method takes into account the spatial uncertainty of rainfall forecasts, increases the spread of the STEPS produced ensemble, and helps smooth the probability output field (Ebert 2008).

At MetService, the NP method is implemented as below:

$$
P_{x}=f\left\{\sum_{i=0}^{N}\left[\omega_{i, x}\left(\sum_{j=0}^{M} R_{i, j, x}\right]\right\}_{c}\right.
$$
where $P_{x}$ is the probability of rainfall at the threshold of $x \mathrm{~mm}$, and $R_{i, j, x}$ is the $j^{\text {th }}$ STEPS ensemble member (at the threshold of $x \mathrm{~mm}$ ) from the base model $i . \omega_{i, x}$ is the weight for the base model $i$. 
187 verification grid aggregated over the previous 12 hours. There may be other metrics that can be used for estimating

$188 \omega_{i, x}$, (e.g., using more than one verification grid for FSS), but the one presented here has been validated to work

189 in MetService's operational environment. More studies may be carried out in the future to evaluate other metrics

190 for NP implementation at MetService.

192 The STEPS ensembles from different base models (with $N$ representing the total number of base models) are 193 combined and then the neighborhood processing, $f$, is applied with the influential range of $c$. At MetService, $c$ is 194 dynamically adjusted using the aggregated FSS for RainCast: the verification grid gradually increases from 1 $195\left(c_{\text {inital }}=1\right)$, and $c$ is recorded when FSS reaches an expected value $F_{\text {exp }}$. Note that $F_{\text {exp }}$ at MetService is 196 threshold dependent (e.g., the expected FSS is 0.75 for the RainCast forecast at the threshold of $0.2 \mathrm{~mm} / \mathrm{h}$ ), and it 197 is determined by the requirement and specific needs of users of RainCast.

\section{3. Case study}

199 A heavy rainfall event from $00 \mathrm{Z}$ to $03 \mathrm{Z}$ on 14 June 2021 over the North Island of New Zealand is selected to 200 demonstrate the pros and cons of RainCast. This event occurred when a mesoscale low over the Tasman Sea (west 201 of North Island) slowly approached the upper North Island, while an associated front and rain band moved south 202 over Northland and Auckland (see Figure 3 for locations). Another front and rain band extended from the low 203 southwards towards Wellington. Figure 2 is a series of combined radar reflectivity images from the New Zealand 204 radar network obtained between $00 \mathrm{Z}$ and $03 \mathrm{Z} 14$ June 2021, which shows that most of the North Island was 205 affected by a broad band of rainfall.

\subsection{Experiment Setup}

To evaluate the model skill between $00 \mathrm{Z}$ and $03 \mathrm{Z}$ on 14 June for different lead times (e.g., T+3 hours and T+24 hours), the forecasts from RainCast and the NWP models are compared. The initialization time of RainCast is different from those of the NWP models, whose availability after initialization are dependent on the operational environment at MetService.

212

213 The NWP models used in this comparison included the Global Forecast System (GFS) from NCEP, the Integrated 214 Forecast System (IFS) from ECMWF, and the Unified Model (UM) from the UKMO, and several LAM models

215 from MetService's operational WRF running at a spatial resolution of $4.0 \mathrm{~km}$. Table 1 gives the RainCast and the corresponding NWP model analysis time (where the notation "nz4kmN-NCEP" represents the WRF model initialized from the GFS global model from NCEP).

In Table 1, the latest NWP analysis time is determined by the arrival time of global model data. For example, MetService receives most new NWP data every 12 hours from runs initialized at $00 \mathrm{Z}$ and $12 \mathrm{Z}$. Therefore, for the duration of this case study, the most recent NWP data available to forecasters would have been from the run initialized at $12 \mathrm{Z}$ on 13 June, however they would not have seen this data until after $16 \mathrm{Z}$ on 13 June. In contrast to the relatively slow delivery of NWP data, the latency of RainCast is approximately only 10-15 minutes, with a moderate computational resource requirement. 


\subsection{Runtime adjusted parameters}

227 In this paper RainCast is "trained" by all the NWP models noted in Table 1. As described in Section 2.2, first the evaluation is carried out for all candidate models so the best possible initial condition(s) for RainCast can be utilized. For example, Figure 4 shows the model weights (at the threshold of $0.2 \mathrm{~mm} / \mathrm{h}$ ) estimated from the objective model evaluation (noted as $\omega_{i, x}$ in Section 2.2) between $12 \mathrm{Z}$ on 13 June and $00 \mathrm{Z}$ on 14 June. According to this figure, the nz4kmN-ECMWF model (with an estimated weight of 0.24) performed better than the others at the evaluation hour, and in RainCast it is assumed that this model would continue to perform well during the entire forecast period. In this case, the lowest contribution for RainCast comes from the GFS model (with a weight of $0.05)$.

The "training" is also performed over the spectral space, as described in the STEPS algorithm (Section 2.1), to merge the extrapolation-based nowcasts with NWP forecasts. Figure 5 shows the scale-dependent skills of nz4kmN-ECMWF against the extrapolation-based nowcasts. The skill of both the nowcast and NWP degrades as the spatial scale decreases (e.g., at a scale of $1650 \mathrm{~km}$ the NWP has a correlation of 0.95 , which decreases to 0.006 when the scale decreases to $11 \mathrm{~km})$.

The relative skills between the nowcast and NWP are also dependent on the spatial scale. For example, at the 1650 $\mathrm{km}$ scale, the extrapolation-based nowcast had better skill relative to the NWP out to $\mathrm{T}+2 \mathrm{~h}$, then after $\mathrm{T}+2 \mathrm{~h}$ its skill declined relative to NWP. Likewise, at the $314 \mathrm{~km}$ scale, the extrapolated nowcast had better skill in comparison to the NWP out to T+3h, then afterwards its skill declined relative to the NWP. At a small scale (e.g., $11 \mathrm{~km})$, there is little skill from the extrapolation-based nowcast, and it is always lower than the NWP forecast.

Operationally, the above training process is carried out with the hourly updated cycle of RainCast. Such a frequent update means that the latest NWP data can be utilized in the parameters' estimation. However, the skill of RainCast could be compromised because the training is performed over the entire domain, and it may not handle well an event in a small area of interest (e.g., an area of most meteorological significance). Moreover, the weights are estimated over the last 12 hours before RainCast's analysis time, which does not necessarily mean these weights will continue to produce the best skills for subsequent forecast hours.

\subsection{Subjective Forecast evaluations}

\subsubsection{Forecast of rainfall probability vs QPE}

Considering the contributions from the extrapolation-based nowcast, RainCast is expected to bring obvious additional value to rainfall prediction within the first 1-2 hours. Additionally, with RainCast multiple NWP models are evaluated and blended with the nowcast so improvements over a longer lead time can also be anticipated. In this section, the predictions for 3-hour rainfall accumulation at the lead time of $T+3 \mathrm{~h}$ and $\mathrm{T}+24 \mathrm{~h}$ are presented and evaluated. 
Figure 6 and Figure 7 compare the RainCast produced probability with the QPE product for the 3-hour rainfall accumulation between $00 \mathrm{Z}$ and $03 \mathrm{Z}$ on 14 June with lead times of 3 hours and 24 hours respectively. The thresholds applied for comparison are $2.0 \mathrm{~mm}, 7.5 \mathrm{~mm}$ and $15.0 \mathrm{~mm}$. Note that although QPE is considered as the ground truth in this paper, it may come with various types of errors (Germann et al., 2006; Giangrande et al., 2008; Zhang et al., 2011; Zhang et al., 2016) which are not discussed in this paper.

From Figure 6, the forecast probability of rain at a low threshold (e.g., 2.0mm) gives a good match to the QPE. For example, high probabilities $(>80 \%)$ of rainfall were predicted in a large area comprising Auckland, Coromandel Peninsula, northern Waikato and western Bay of Plenty (see Figure 3 for locations. Coromandel Peninsula is between Auckland and Bay of Plenty). High probabilities (between 50\% and 90\%) were given in Wellington, while relatively lower probabilities (between $30 \%$ and 50\%) were shown along the coast of the Manawatu-Wanganui region. The skill of RainCast decreases with an increased threshold. For example, the area with rainfall over $15.0 \mathrm{~mm}$ was overestimated (although with relatively low probabilities), especially in the Wellington region.

The skill of RainCast decreases with increasing lead hours. For example, Figure 7 gives the forecast rainfall probability at the lead time of 24 hours. Compared to Figure 6, RainCast for the $2.0 \mathrm{~mm}$ threshold clearly overpredicted in areas. For example, in the area including Taihape (central North Island) and inland Manawatu, RainCast had a probability of greater than $30 \%$ of rain during the period of interest, whereas QPE showed it to be dry. Moreover, little skill was shown when the threshold was increased to $7.5 \mathrm{~mm}$.

The above study suggests that for this event, RainCast was generally good at distinguishing between wet and dry areas although there were some overestimates (e.g., where the QPE showed it was dry, RainCast indicated a probability of light or moderate precipitation). However, RainCast struggled to produce satisfactory results for moderate-heavy rainfall intensities (e.g., $15 \mathrm{~mm}$ for a 3-hour period), especially when the lead time was longer than 3 hours.

\subsubsection{RainCast derived deterministic forecast vs other NWPs}

To compare RainCast's probabilistic forecasts with the deterministic rain forecasts from other models (i.e., IFS,

292 GFS, UM and WRF) used at MetService, three RainCast percentage probability levels were chosen to function as pseudo "deterministic" rain forecasts. The percentage thresholds extracted from RainCast for this purpose were $25 \%, 50 \%$ and $75 \%$.

Figure 8 shows the 3-hour rainfall accumulation forecasts from RainCast, IFS, GFS, UM, nz4kmN-NCEP, nz4kmN-ECMWF and nz4kmN-UKMO, and they are compared to the QPE accumulation between 00Z and 03Z on 14 June 2021 (model analysis time as in Table 1).

300 With reference to Figure 8, the IFS, RainCast (>25\%) and RainCast $(>50 \%)$ provided reasonable matches to the 301 QPE, especially in Northland, Auckland and Waikato. All three versions of RainCast, as well as the IFS and 302 UM models, compared reasonably well with the QPE for predicting rain in southern areas of Waikato, whereas 
304 forecast much more rain than shown by the QPE over eastern Bay of Plenty and northern Taranaki, while all

305 three RainCast versions noticeably had much more rain in Wellington compared to the QPE. Overall, IFS and

306 the two RainCast versions (>25\% and 50\%) appear to have outperformed the others in this subjective

307 comparison.

309 As already noted, in contrast to the QPE there was significant rainfall predicted by many of the models (including

310 RainCast) over eastern Bay of Plenty. A reason for this is that radar coverage of the area is compromised. The

311 distance to the radar station in the western Bay of Plenty means that the low-tropospheric rain cannot be observed

312 well with the QPE underestimating the rain as a result, while the radar station in Hawkes Bay will suffer from

313 beam blocking in the lowest elevations to the north/northwest. Installing and using more rain gauges in the radar

314 rainfall calibration process could provide us with a better QPE map, which is a possibility for future improvement.

316 Similar to Figure 8, when the lead time was 24 hours (Figure 9), IFS and the two RainCast forecasts (>25\% and

$31750 \%$ ) seemed generally to outperform the other models. However, these three approaches under-forecasted rain

318 along the coast of Waikato, although the RainCast (>25\%) was slightly better than the other two. There are

319 massive overestimates in the Bay of Plenty compared to the QPE. Some spurious showers were presented in the

320 Manawatu-Wanganui region from IFS and RainCast (>25\%), which were successfully eliminated when the 321 probability threshold increased to $50 \%$ in RainCast. In contrast, the rest of the models (e.g., GFS, UM and all

322 WRFs) did not give good predictions for a lead time of 24 hours.

The above indicates that RainCast was overall able to provide improved forecasts compared to most individual NWP approaches, especially over a short range (e.g., < 3 hours). For this event IFS gave comparable results to RainCast. However, to evaluate the ability of RainCast over a longer period, a more quantitative and less subjective evaluation approach must be adopted, which is described in Section 4.

\section{4. Objective verification}

329 Section 3 provides a subjective evaluation of the event that occurred between $00 \mathrm{Z}$ and $03 \mathrm{Z}$ on 14 June. However, 330 such an evaluation is not carried out quantitatively, and it is prone to individual biases of interpretation (e.g., 331 Stanski et al., 1989). To objectively validate the accuracy of forecasts, it is more useful to calculate the FSS over 332 a longer period, as presented here for the period 00Z 1 June 2021 to 30 June 2021. During this period numerous 333 rain-producing systems of varied intensities affected the country (the case presented in Section 3 is one of the 334 events that occurred during this period).

336 One of the challenges of applying the FSS is the different spatial resolutions of the models. For example, the 337 effective QPE resolution for New Zealand is $5.0 \mathrm{~km}$, while RainCast, IFS, GFS, UM and WRF (including $338 \mathrm{nz} 4 \mathrm{kmN}-\mathrm{NCEP}, \mathrm{nz} 4 \mathrm{kmN}-\mathrm{UKMO}$ and nz4kmN-ECMWF) have resolutions of approximately $5.0 \mathrm{~km}, 9.0 \mathrm{~km}$, $33922.0 \mathrm{~km}, 25.0 \mathrm{~km}$ and $4.0 \mathrm{~km}$, respectively. To calculate the FSS, all the models are re-projected to the QPE grid, 340 meaning that the base resolution for the verification is $5.0 \mathrm{~km}$ which may be different to the effective resolution 341 of a particular model. Figure 10 shows the FSS with different thresholds $(0.5 \mathrm{~mm}, 7.5 \mathrm{~mm}$ and $15.0 \mathrm{~mm})$ on 
verification grids of $1(5.0 \mathrm{~km})$ and $5(25.0 \mathrm{~km})$, respectively. The scores are calculated by validating 3-hour rain accumulations at 3 hourly intervals throughout the 1 month duration.

At a threshold of $0.5 \mathrm{~mm}$ RainCast (>25\%) outperformed all the other models over the entire 24 hours, (Figure 10A and 10B). IFS produced the highest skill score among the global NWP models. UM scored the lowest over the aggregation period with 1 verification grid, however its performance improved when the number of verification grids increased. For example UM performed better than RainCast ( $>75 \%)$ when the grid increased to 5, (Figure 10B). Verification also indicates that RainCast (>75\%) gave a low number of both "hits" and "false alarms", and on average its skill is lower than most other forecast approaches at such a small verification threshold.

When the threshold increased to $7.5 \mathrm{~mm}$ (Figure 10C and 10D), the skill of RainCast (> 25\%) dropped below IFS and nz4kmN-ECMWF, especially after 3-6 hours. RainCast (>75\%) provided the best forecasts from the FSS point of view, followed by RainCast (>50\%). On average, IFS still ranked third among all forecast approaches. Moreover, the skill of UM increased with increased verification scale. For example, UM performed slightly better than the nz $4 \mathrm{kmN}$-UKMO when the number of verification grids increased to 5 , especially after $\mathrm{T}+12$ hours. example, the average skill for all forecast approaches dropped from 0.65 (threshold of $0.5 \mathrm{~mm}$ using 1 verification grid, Figure 10A) to 0.13 (threshold of $15.0 \mathrm{~mm}$ using 1 verification grid, Figure 9E). Similar to the verification with a threshold of $7.5 \mathrm{~mm}$, RainCast (>75\%) on average still performed the best from the FSS point of view, especially for the first 3-6 hours. In contrast to the verifications with lower thresholds (Figure 10A, 10B, 10C and 10D), IFS outperformed RainCast ( $>50 \%)$. On the other hand, RainCast ( $>25 \%)$ did not provide satisfactory results due to its overestimates at such a threshold. "goodness" or "usefulness" of the forecast. From an operational forecast point of view, "consistency", "quality" and "value" are the three essential metrics which determine the usefulness of a forecast (e.g., Murphy, 1993, 1995), while objective verification mainly provides a reference for the forecast quality.

RainCast frequently uses the latest available observations, and this inevitably means that the user will have to expect more inconsistencies from updated forecasts cycle by cycle. Moreover, since RainCast is a statistical system and is not constrained by physical laws which the NWP-based systems are, this could lead to discrepancies between the output from RainCast and the forecaster's best judgement about the situation, which usually takes many meteorological factors into account.

Additionally, the above objective verification is carried out and averaged over the entire New Zealand domain, which may not optimally reflect the situation in an area or areas where there are more meteorological values of significance (e.g., a thunderstorm in a city is likely to have greater impact than one which occurs in an uninhabited area). Therefore, even though the FSS has value in quantifying how RainCast performs, it will take longer in an operational environment to fully realise the benefits that can be gained by decision makers using its forecasts. 


\section{Discussion:}

383 The skills of RainCast were demonstrated in both Section 3 and Section 4. In this section, the system limitations and potential improvements are discussed.

RainCast uses radar data to produce extrapolated nowcasts, and to evaluate the initial conditions of the different NWP models for the current hour (or latest RainCast analysis time). The QPE data, which is used to verify the results from RainCast and other forecast models, are also largely dependent on radar data. Therefore, the quality of radar data plays an essential role in the running of RainCast, and consequently the skill of the system is dependent on it, especially for the first few hours.

The topography of New Zealand is complex, especially in the South Island. For example, the Southern Alps run almost along the whole length of the island, which are approximately $800 \mathrm{~km}$ long and more than $60 \mathrm{~km}$ wide, and therefore forms an effective barrier between western and eastern areas of the island. Consequently, New Zealand's complex orography often obstructs low-level radar beams, degrading the performance of radar-based nowcasting (e.g., Foresti and Seed, 2015).

Another major uncertainty from the use of radar data is the Z-R relationship. At MetService, a customized Z-R relationship is used to convert radar observed reflectivity to rainfall amounts. This Z-R relationship is updated hourly by regressing the $\mathrm{dBZ}$ to gauge-observed rainfall (not presented in this paper). It is demonstrated in an operational environment that this dynamically adjusted Z-R relationship matches the rain gauge records more accurately for New Zealand than the Marshall-Palmer distribution $Z=200 R^{1.6}$ (Marshall and Palmer, 1948), but still underestimates many significant events, especially when the reflectivity is greater than 20-25 dBZ.

Since a lot of rain gauge data cannot be retrieved in a timely manner to correct it for use in RainCast, there will consequently be underestimates in the extrapolation-based nowcasts, and thus a downgrade in the performance of RainCast, especially for the first 1 to 3 hours. This issue will also affect RainCast's initial conditions and forecast evaluation, since the QPE, which is largely derived from radar data, is here considered as the "ground truth". It is recommended that an improved radar quality control system is needed to further improve the skill of RainCast.

411 As described in Section 2, there are multiple NWP models used in RainCast and they are blended with an extrapolation-based nowcast. The contribution from an individual NWP model is dependent on its skill over a

413 predefined aggregation period (usually it is between $\mathrm{T}+0 \mathrm{~h}$ and $\mathrm{T}+12 \mathrm{~h}$ where $\mathrm{T}+0 \mathrm{~h}$ is the RainCast analysis time). 414 However, such a skill does not necessarily reflect the model's performance for subsequent hours, especially if 415 there are changes to how a weather situation evolves. Moreover, this skill is estimated over the entire RainCast 416 domain, and the domain average skill may not represent a particular area of interest (e.g., airports, urban centres 417 with dense populations and areas exposed to the highest risk of flooding). One of the potential improvements that 418 could be made in the future is to run RainCast over a smaller domain specifically for the area with the most 419 meteorological value. 


\section{Summary:}

421 The hourly updated RainCast system at MetService has been described. The algorithm for this system is adapted

422 from STEPS with a neighborhood processing method applied. This system is in the process of being implemented 423 operationally at MetService. Evaluation suggests that, compared to the NWP alone approach, RainCast could 424 improve precipitation forecasts in New Zealand out to 24 hours, particularly for light to moderate rainfall events, 425 with the greatest improvements in the first 1-3 hours.

426

427 Acknowledgement

428 The authors thank several MetService operational forecasters for providing valuable feedback during the RainCast forecast demonstration project. The authors also thank Dr. Alan Seed (Bureau of Meteorology, Australia) for

430 providing suggestions and guidance on the implementation of the STEPS algorithm in New Zealand. The idea of blending multiple models was inspired by Dr. Xiang-yu Huang (Meteorological Service Singapore) and Dr. Juanzhen Sun (National Center for Atmospheric Research, Boulder, USA). Global model data were obtained from NCEP, UK Met Office and ECMWF. The WRF model was developed and provided by NCAR. Some of the rain

434 gauge observations used in this paper were provided by the local regional councils in New Zealand.

435

436

437

438

\section{References}

439

Barker, D. M., W. Huang, Y.R. Guo, A. J. Bourgeois and Q. N. Xiao (2004). A three-dimensional variational data assimilation system for MM5: Implementation and initial results. Mon. Wea. Rev., 132, 897-914.

440 Benjamin, S. G., et al. (2004a). An hourly assimilation/forecast cycle: The RUC. Mon. Wea. Rev.,132, $495-518$.

441 Benjamin, S. G., et al. (2016). A North American hourly assimilation and model forecast cycle: The Rapid Refresh. 442 Mon. Wea. Rev.,144, 1669-1694.

443 Bowler, N. E., Pierce, C. E., and Seed, A. W. (2006). STEPS: A probabilistic precipitation forecasting scheme 444 which merges an extrapolation nowcast with downscaled NWP, Q. J. R. Meteorol. Soc., 132, $2127-2155$.

445 Browning, K. A. (1980). Local weather forecasting. Proc. Roy. Soc. London, A371, 179-211.

446 Clark, A. J., J. Gao, P. T. Marsh, T. Smith, J. S. Kain, J. Correia, M. Xue, and F. Kong (2013). Tornado 447 pathlength forecasts from 2010 to 2011 using ensemble updraft helicity. Wea. Forecasting, 28, 387-407.

448 Dixon, M. and G. Wiener (1993). TITAN: Thunderstorm Identification, Tracking, Analysis, and Nowcasting-A 449 radar-based methodology. J. Atmos. Oceanic Technol., 10, 785-797.

450 Ebert, E. (2008). Fuzzy verification of high-resolution gridded forecasts: A review and proposed 451 framework. Meteor. Appl., 15, 51-64. 
452 Foresti, L.; Seed, A. (2015). On the spatial distribution of rainfall nowcasting errors due to orographic forcing.

453 Meteorol. Appl. 2015, 22, 60-74.

454 Gagne, D. J., A. McGovern, J. Brotzge, M. Coniglio, J. Correia Jr., and M. Xue (2015). Day-ahead hail 455 prediction integrating machine learning with storm-scale numerical weather models. 27th Conf. on Innovative 456 Applications of Artificial Intelligence, Austin, TX, Association for the Advancement of Artificial 457 Intelligence, 3954-3960.

458 Germann, U., and I. Zawadzki (2002). Scale-dependence of the predictability of precipitation from continental 459 radar images. Part I: Description of the methodology. Mon. Wea. Rev., 130, 2859-2873.

460 Germann, U., G. Galli, M. Boscacci, and M. Bolliger (2006). Radar precipitation measurement in a mountainous 461 region. Quart. J. Roy. Meteor. Soc., 132, 1669-1692.

462 Giangrande, S. E., and A. V. Ryzhkov (2008). Estimation of rainfall based on the results of polarimetric echo 463 classification. J. Appl. Meteor. Climatol., 47, 2445-2462.

464 Haiden, T., Kann, A., Wittmann, C., Pistotnik, G., Bica, B., and Gruber, C. (2010). The Integrated Nowcasting 465 through Com- prehensive Analysis (INCA) System and Its Validation over the Eastern Alpine Region, Wea. 466 Forecasting, 26, 166-183.

467 Jirak, I. L., C. J. Melick, and S. J. Weiss (2014). Combining probabilistic ensemble information from the 468 environment with simulated storm attributes to generate calibrated probabilities of severe weather hazards. 27 th 469 Conf. on Severe Local Storms, Madison, WI, Amer. Meteor. Soc., 2.5, https://ams.confex.com/ams/ 470 27SLS/webprogram/Paper254649.html.

471 Lovejoy, S. D. Schertzer (2006). Multifractals, cloud radiances and rain, J. Hydrol. 322, 59-88.

472 Lynn, B. H., G. Kelman, and G. Ellrod (2015). An evaluation of the efficacy of using observed lightning to 473 improve convective lightning forecasts. Wea. Forecasting, 30, 405-423.

474 Mittermaier, M. (2014). A strategy for verifying near-convection-resolving forecasts at observing sites. Wea. 475 Forecasting, 29, 185-204.

476 Marshall, J. S. and Palmer, W. M. (1948): The distribution of raindrops with size, J. Meteor., 5, $165-166$.

477 Milan, M., Macpherson, B., Tubbs, R. (2020). Hourly 4D-Var in the Met Office UKV operational forecast 478 model. Q. J. R. Meteorol. Soc. 146, 1281- 1301.

479 Murphy, A.H. (1993). What is a good forecast? An essay on the nature of goodness in weather forecasting. Wea. 480 Forecasting, 8, 281-293. 
481 Murphy, A.H. (1995). The coefficients of correlation and determination as measures of performance in forecast

482 verification. Wea. Forecasting, 10, 681-688.

483 Huang, X.-Y., et al. (2009). Four-dimensional variational data assimilation for WRF: Formulation and 484 preliminary results. Mon. Wea. Rev., 137, 299-314.

485 Roberts, N. M., and H. W. Lean (2008). Scale-selective verification of rainfall accumulations from high486 resolution forecasts of convective events. Mon. Wea. Rev., 136, 78-97.

487 Schwartz, C.S., et al. (2010). Toward Improved Convection-Allowing Ensembles: Model Physics Sensitivities 488 and Optimizing Probabilistic Guidance with Small Ensemble Membership. Wea. Forecast, 25, $263-280$.

489 Schwartz, C.S. and Ryan A.S. (2017). Generating Probabilistic Forecasts from Convection-Allowing Ensembles

490 Using Neighbourhood Approaches: A Review and Recommendations. Mon. Wea. Rev. 2017, 145(9), 3397-341.

491 Seed, A. W. (2003). A Dynamic and Spatial Scaling Approach to Advection Forecasting, J. Appl. Meteor., 42, $492 \quad 381-388$.

493 Seed, A.E., C. E. Pierce, and K. Norman. (2013). Formulation and evaluation of a scale decomposition-based 494 stochastic precipitation nowcast scheme. Water Resources Research, 49(10): 6624-6641.

495 Snyder, C., and F. Zhang (2003). Assimilation of simulated Doppler radar observations with an ensemble Kalman 496 filter. Mon. Wea. Rev., 131, 1663-1677.

497 Skamarock, W. C., et al. (2008). A description of the Advanced Research WRF version 3. NCAR Tech. Note. 498 NCAR/TN-4751STR, 113 pp.

499 Sobash, R. A., J. S. Kain, D. R. Bright, A. R. Dean, M. C. Coniglio, and S. J. Weiss. (2011). Probabilistic forecast 500 guidance for severe thunderstorms based on the identification of extreme phenomena in convection-allowing 501 model forecasts. Wea. Forecasting, 26, 714-728.

502 Sobash, R. A., C. S. Schwartz, G. S. Romine, K. R. Fossell, and M. L. Weisman (2016). Severe weather 503 prediction using storm surrogates from an ensemble forecasting system. Wea. Forecasting, 31, $255-271$.

504 Stanski, H.R., L.J. Wilson, and W.R. Burrows (1989). Survey of common verification methods in meteorology. 505 World Weather Watch Tech. Rept. No.8, WMO/TD No.358, WMO, Geneva, 114 pp.

506 Sun, J., M. Chen and Y. Wang (2010). A frequent-updating analysis system based on radar, surface, and 507 mesoscale model data for the Beijing 2008 forecast demonstration project. Wea. Forecasting, 25, 1715-1735.

508 Sun, J., S. B. Trier, Q. Xiao, M. L. Weisman, H. Wang, Z. Ying, M. Xu, and Y. Zhang (2012). Sensitivity of 0509 12-h warm-season precipitation forecasts over the central United States to model initialization. Wea. $510 \quad$ Forecasting, 27, 832-855. 
511 Theis, S. E., A. Hense, and U. Damrath (2005). Probabilistic precipitation forecasts from a deterministic model:

512 A pragmatic approach. Meteor. Appl., 12, 257-268.

513 Wang, X. G., Parrish, D., Kleist, D., \& Whitaker, J. (2013). GSI 3DVarbased ensemble-variational hybrid data 514 assimilation for NCEP global forecast system: Single-resolution experiments. Monthly Weather Review, 141, $515 \quad 4098-4117$.

516 Wilson, J. W., and R. D. Roberts (2006). Summary of convective storm initiation and evolution during IHOP: 517 Observational and modelling perspective. Mon. Wea. Rev., 134, 23-47.

518 Xiao, Q., Y.-H. Kuo, J. Sun, W.-C. Lee, D. M. Barker, and E. Lim. (2007). An approach of radar reflectivity data 519 assimilation and its assessment with the inland QPF of Typhoon Rusa (2002) at landfall. J. Appl. Meteor. 520 Climatol., 46, 14-22.

521 Zhang, J., et al. (2011). National mosaic and multi-sensor QPE (NMQ) system: Description, results, and future 522 plans. Bull. Amer. Meteor. Soc., 92, 1321-1338.

523 Zhang, J., et al. (2016). Multi-Radar Multi-Sensor (MRMS) quantitative precipitation estimation: Initial operating 524 capabilities. Bull. Amer. Meteor. Soc., 97, 621-638.

525 Zhang, S., G. Austin, and L. Sutherland. (2014). The implementation of reverse Kessler warm rain scheme for 526 radar reflectivity assimilation using a nudging approach in New Zealand. Asia-Pacific J. Atmos. Sci., $\underline{50}(\underline{3}), 283-$ 527296. 
Figures

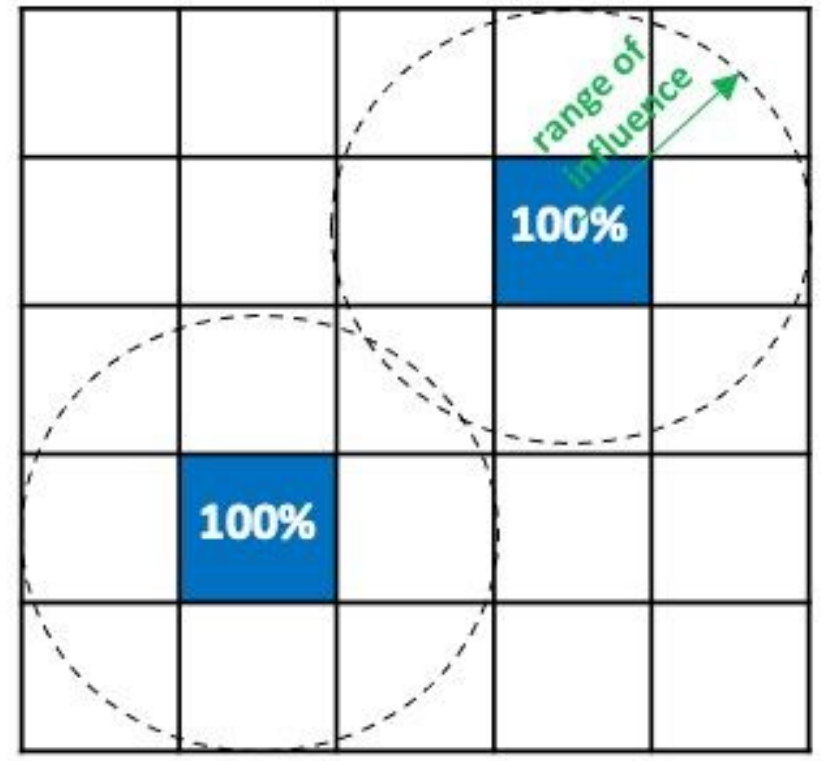

(a): Before NP: two grid points, A and $B$, each with a $100 \%$ of probability of rain

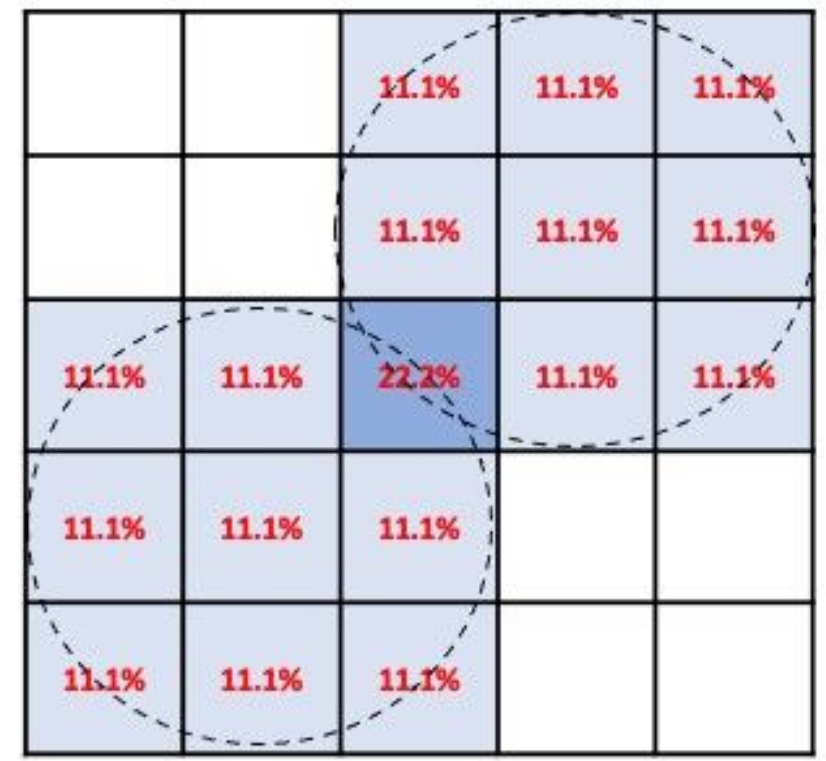

(b): After NP, with a 1 grid range of influence, 1 grid has a $22.2 \%$ probability of rain, and 16 grids each have a $11.1 \%$ probability of rain.

\section{Figure 1}

An illustrated description of neighborhood processing (probabilities are calculated to three significant figures) 

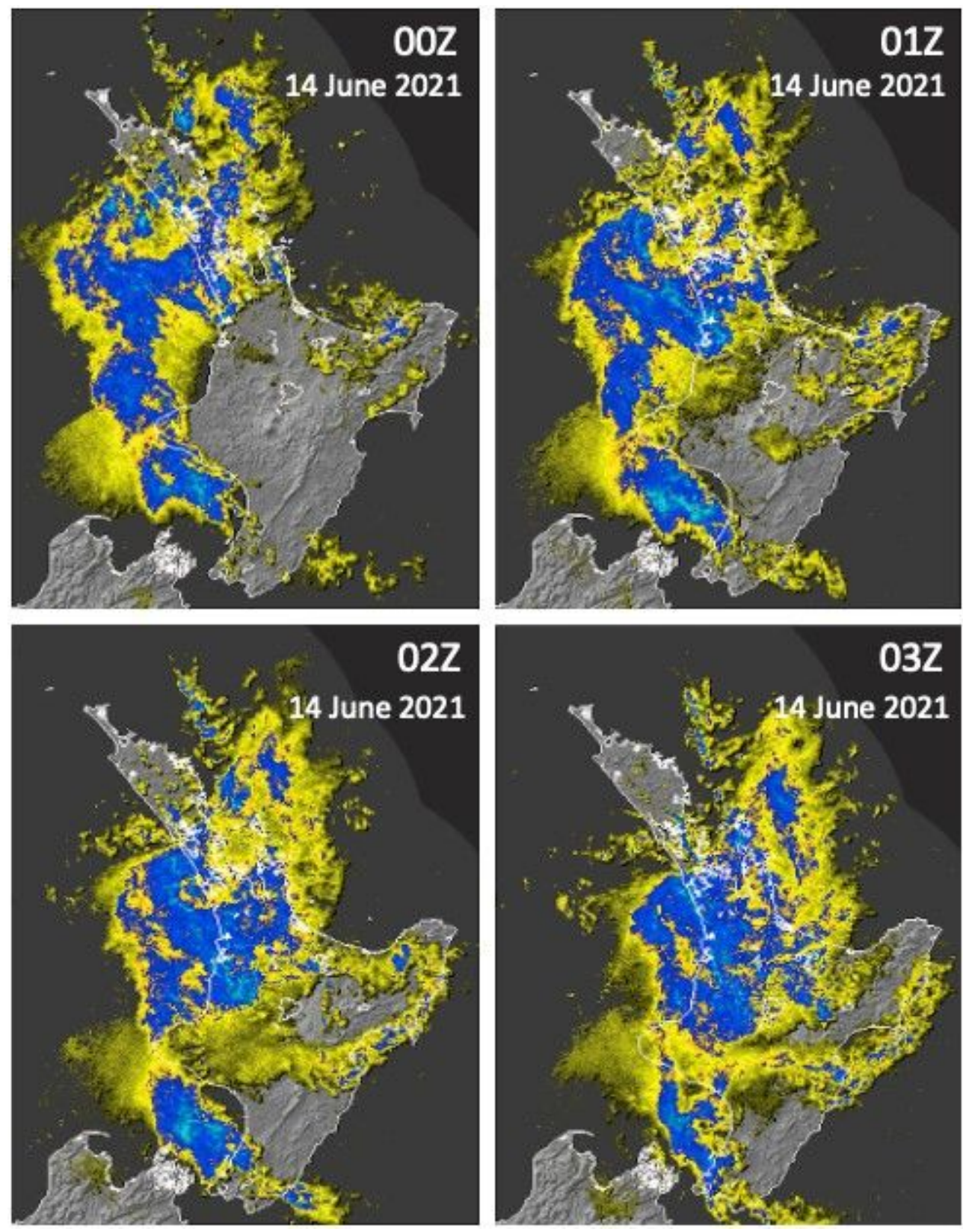

Figure 2

A series of radar reflectivity images between $00 Z$ and $03 Z 14$ June 2021. 


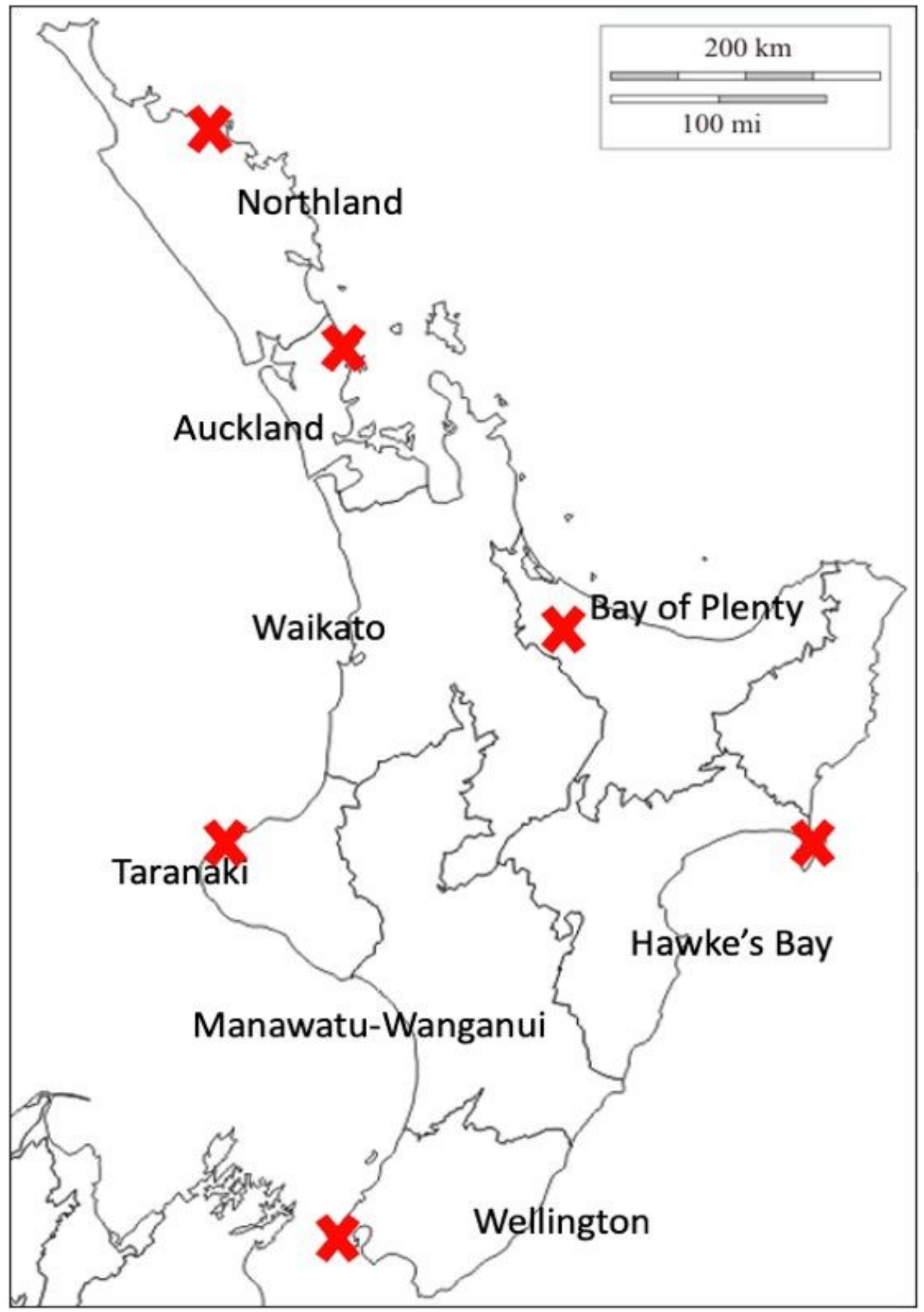

Figure 3

Regions of the North Island of New Zealand (courtesy to LGNZ: https://www.lgnz.co.nz), and locations of the rain radars (red crosses). 


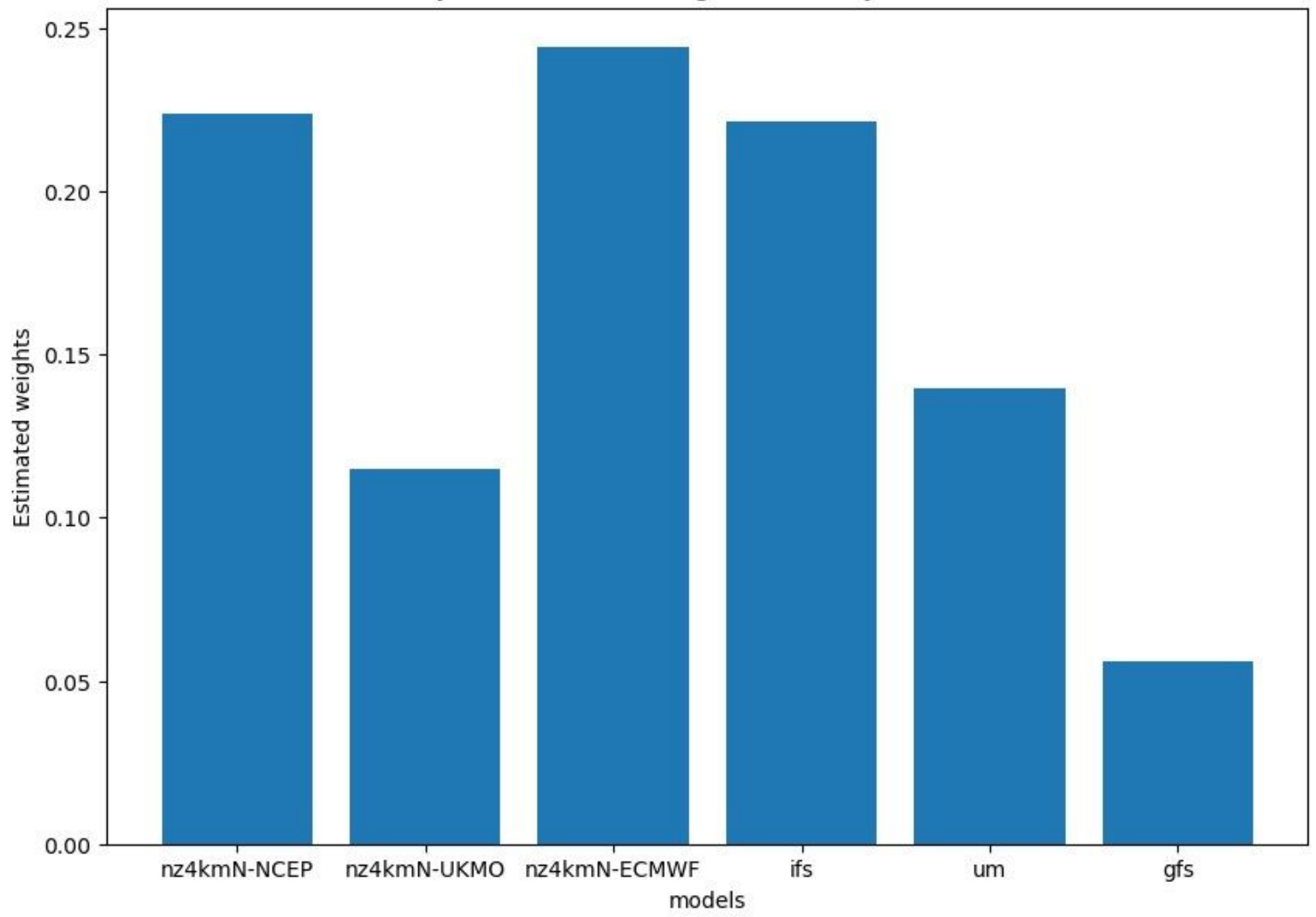

Figure 4

Dynamically adjusted weights at 00Z 14 June 2021 for all available NWP models. 

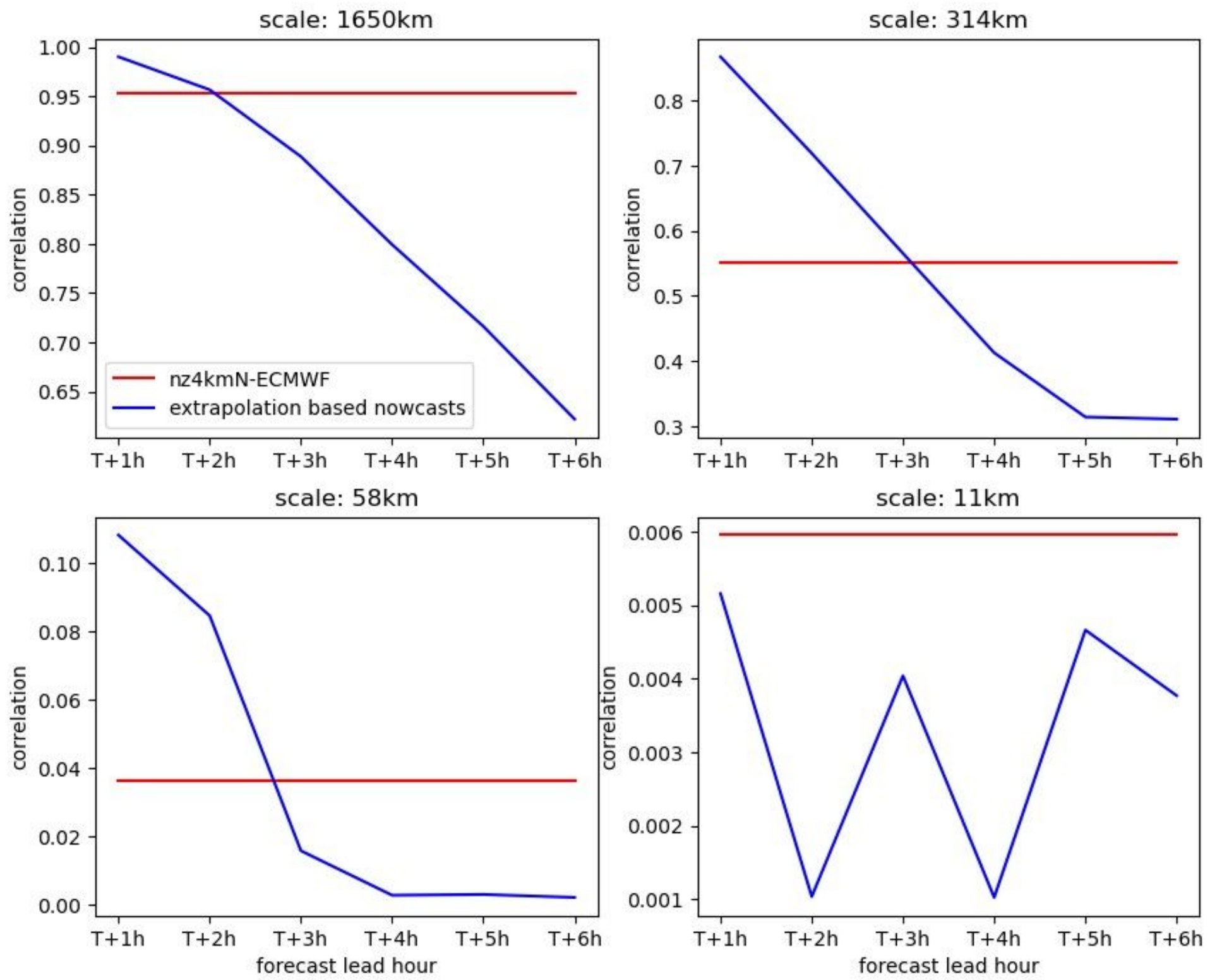

Figure 5

Correlations between the extrapolation-based nowcasts (blue) and NWP (red) for different spatial scales (updated at $00 Z 14$ June 2021). 


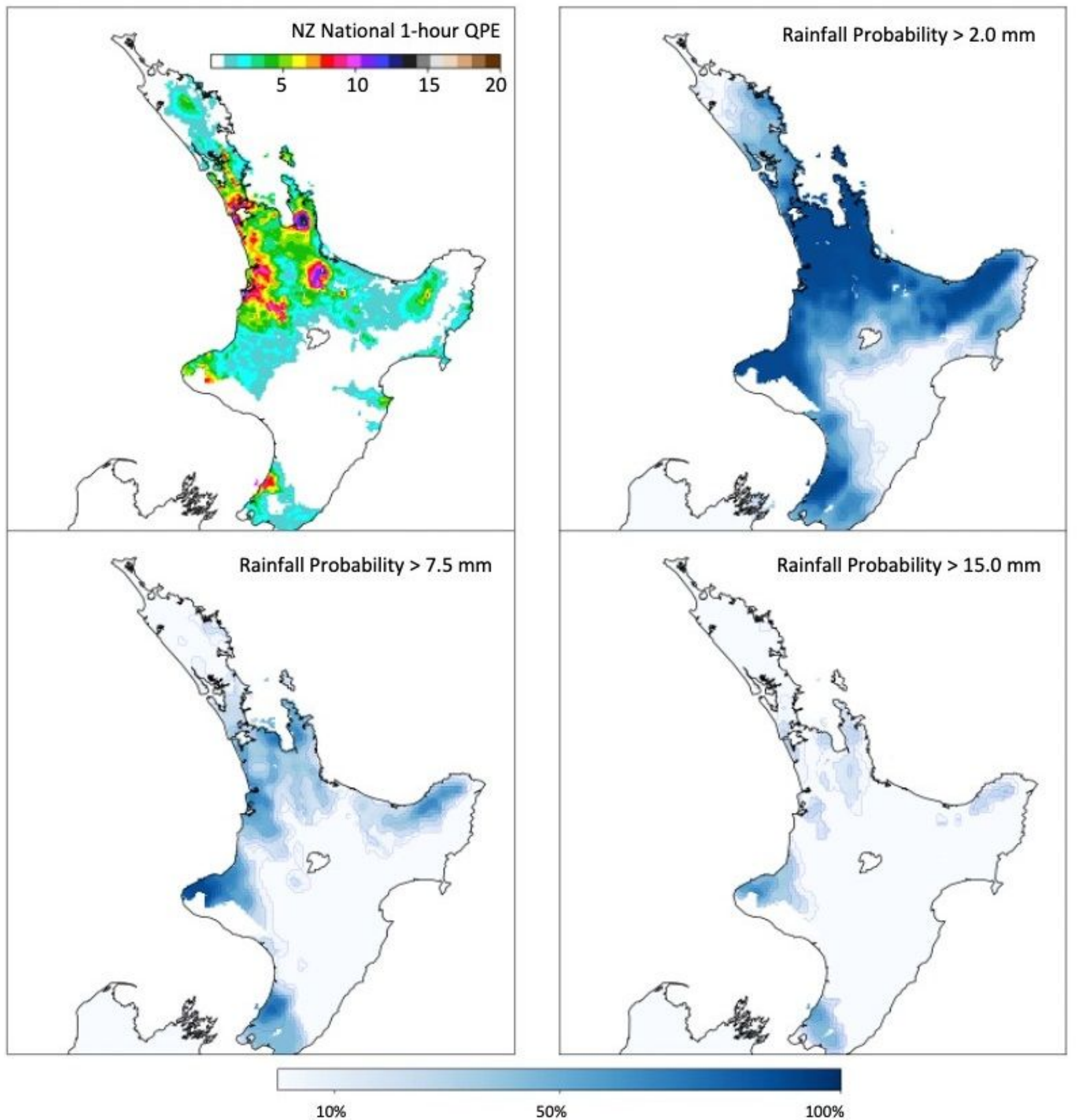

Figure 6

RainCast rainfall probability (3-hour accumulation) between $00 Z$ and $03 Z, 14$ June 2021, and the corresponding QPE (top-left). The RainCast analysis time is 00Z 14 June 2021. 


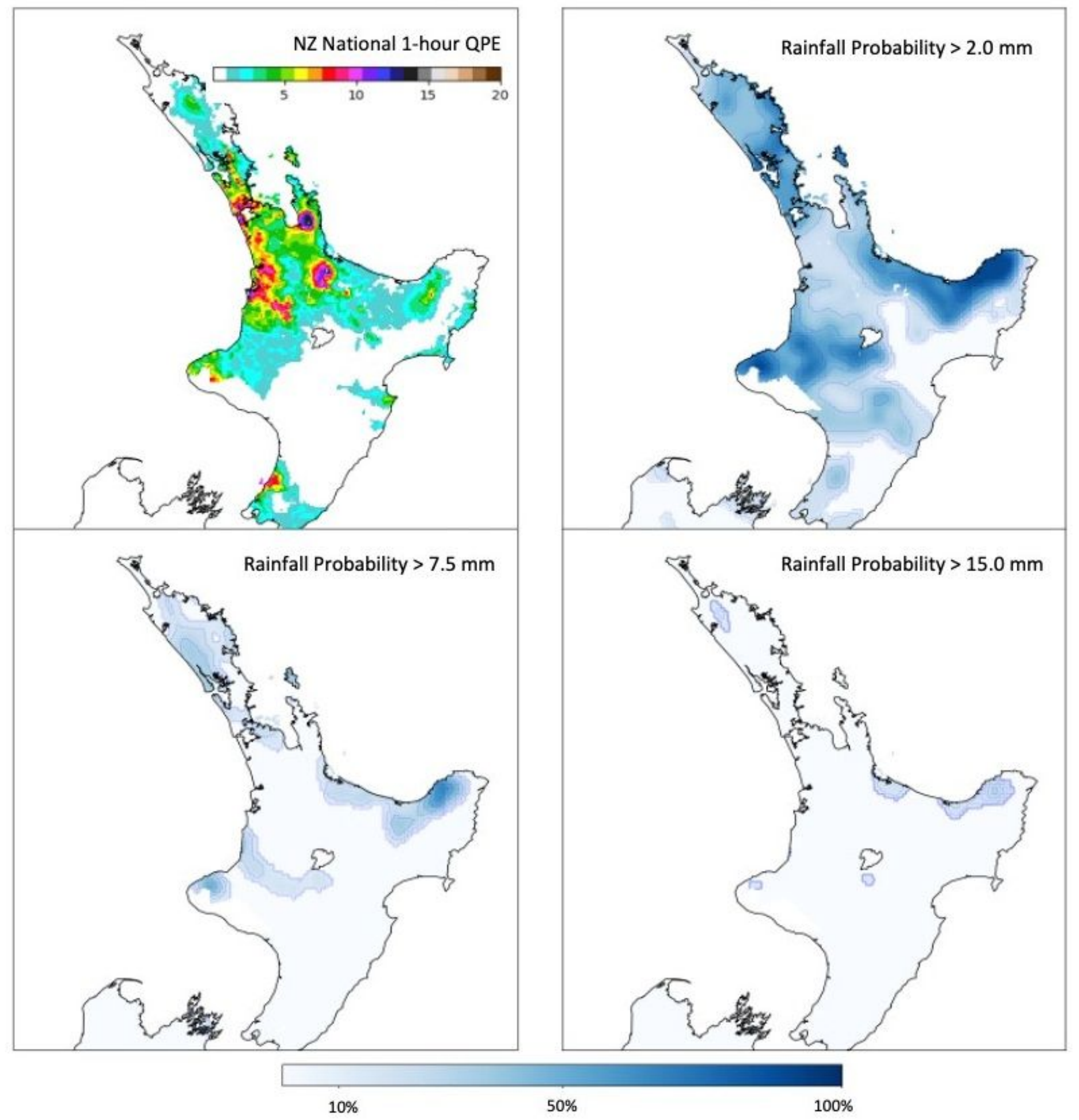

Figure 7

As Figure 6, but the RainCast analysis time is $03 Z 13$ June 2021. 


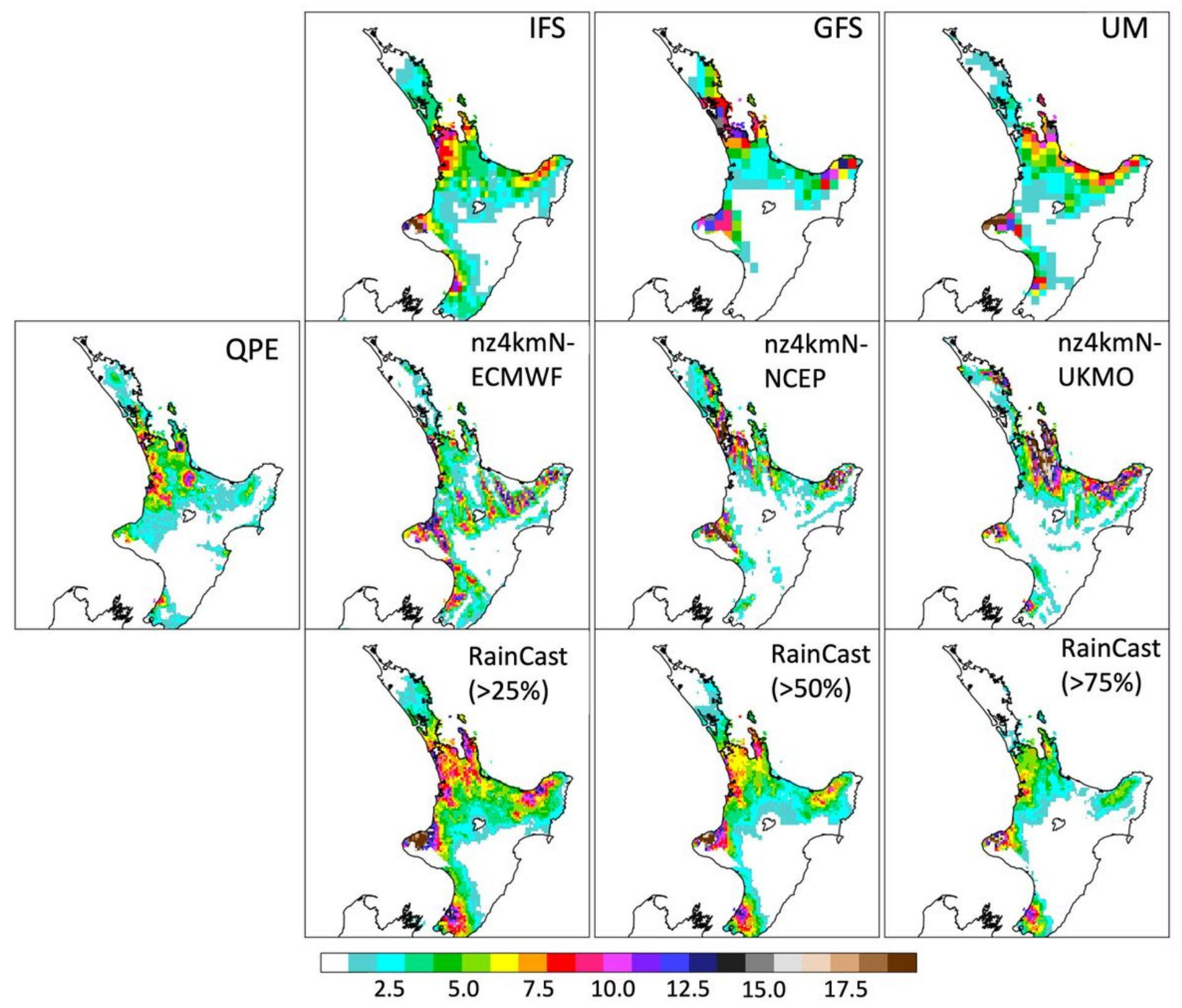

Figure 8

QPE (far left) and 3-hour rainfall accumulations valid between 00Z and $03 Z 14$ June 2021 for nine different forecast approaches. Analysis times for the models are as in Table 1. 


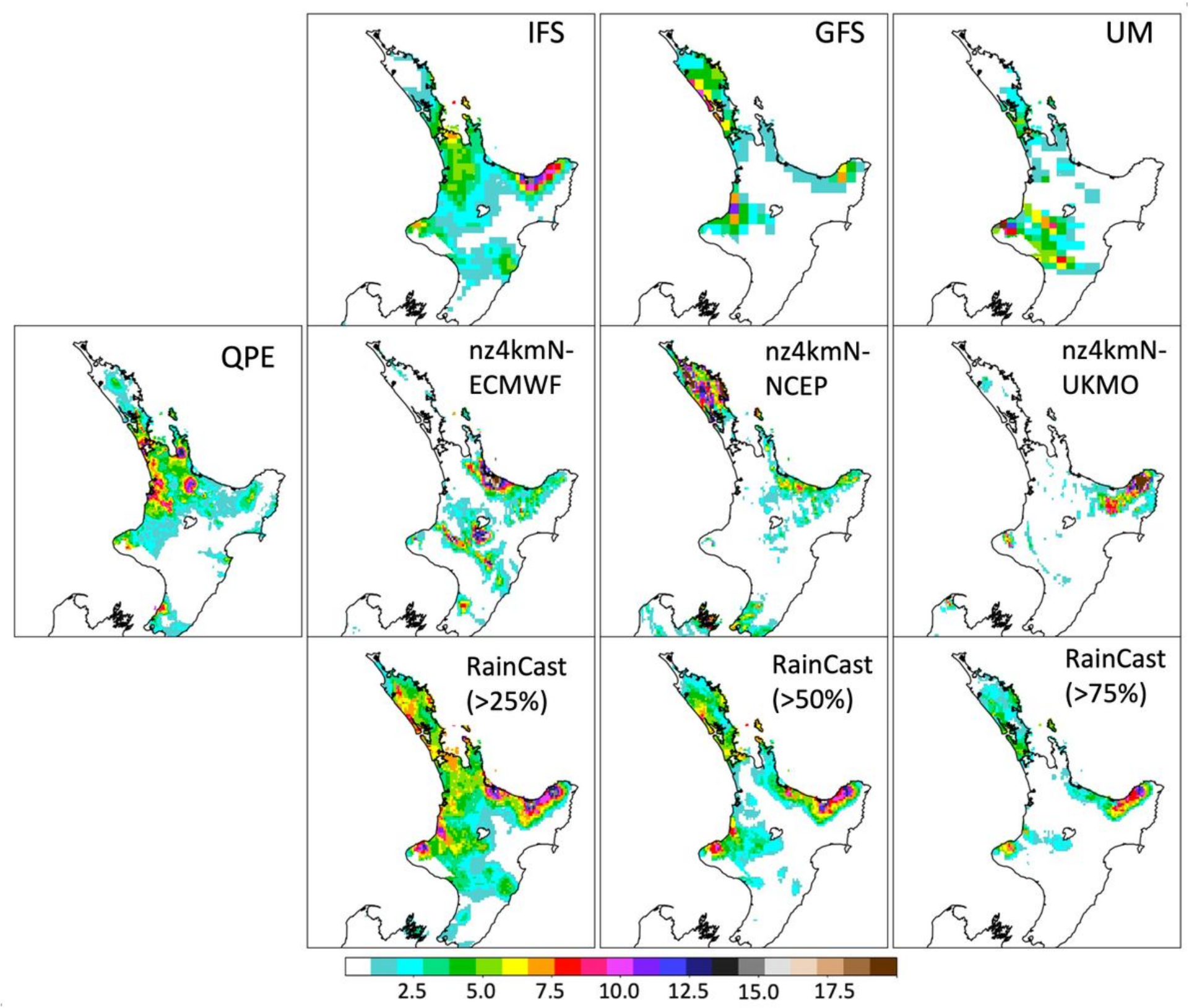

Figure 9

As Figure 8, but with forecast lead time of 24 hours. 
Fractional Skill Score, $00 Z 01$ June - $23 Z 30$ June 2021

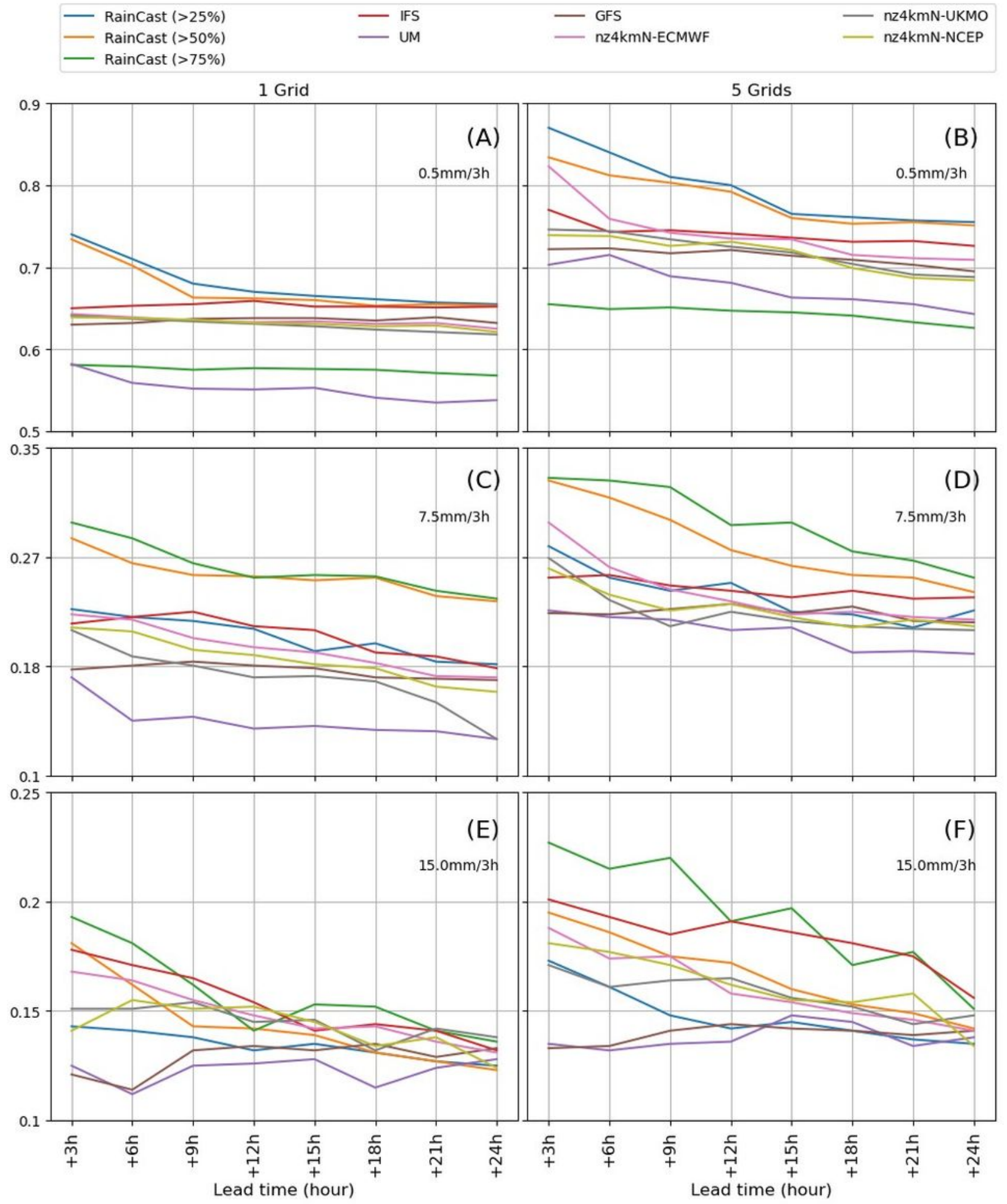

Figure 10

FSS aggregated between 00Z 1 June and $23 Z 30$ June 2021. 